\title{
Modulation by chronic stress and ketamine of ionotropic AMPA/NMDA and metabotropic glutamate receptors in the rat hippocampus
}

\author{
Mohammed E.A. Elhussiny ${ }^{\mathrm{a}, 1}$, Giulia Carini ${ }^{\mathrm{a}, 1}$, Jessica Mingardi ${ }^{\mathrm{a}}$, Paolo Tornese ${ }^{\mathrm{b}}$, Nathalie Sala ${ }^{\mathrm{b}}$, \\ Federica Bono ${ }^{\mathrm{c}}$, Chiara Fiorentini ${ }^{\mathrm{c}}$, Luca La Via ${ }^{\mathrm{a}}$, Maurizio Popoli ${ }^{\mathrm{b}}$, Laura Musazzi ${ }^{\mathrm{b}, 1,2}$, \\ Alessandro Barbon ${ }^{\mathrm{a}, 1, *}$ \\ ${ }^{a}$ Division of Biology and Genetics, Department of Molecular and Translational Medicine, University of Brescia, Brescia, Italy \\ ${ }^{\mathrm{b}}$ Laboratory of Neuropsychopharmacology and Functional Neurogenomics, Dipartimento di Scienze Farmaceutiche, Sezione di Fisiologia e Farmacologia, Università degli \\ Studi di Milano, Milan, Italy \\ ${ }^{\mathrm{c}}$ Division of Pharmacology, Department of Molecular and Translational Medicine, University of Brescia, Brescia, Italy
}

\section{A R T I C L E I N F O}

\section{Keywords:}

Chronic mild stress

Stress vulnerability

Ketamine

Antidepressant

Glutamate receptors

RNA editing

\begin{abstract}
A B S T R A C T
Converging clinical and preclinical evidence has shown that dysfunction of the glutamate system is a core feature of major depressive disorder. In this context, the $N$-methyl-D-aspartate (NMDA) receptor antagonist ketamine has raised growing interest as fast acting antidepressant.

Using the chronic mild stress (CMS) rat model of depression, performed in male rats, we aimed at analyzing whether hippocampal specific changes in subunit expression and regulation of $\alpha$-amino-3-hydroxy-5-methyl-4isoxazolepropionic acid (AMPA) or NMDA ionotropic receptors and in metabotropic glutamate receptors could be associated with behavioral vulnerability/resilience to CMS. We also assessed whether acute ketamine (10 mg/ $\mathrm{kg}$ ) was able to dampen the alterations in CMS vulnerable animals.

Although chronic stress and ketamine had no effect on ionotropic glutamate receptors mRNAs (expression, RNA editing and splicing), we found selective modulations in their protein expression, phosphorylation and localization at synaptic membranes. AMPA GluA2 expression at synaptic membranes was significantly increased only in CMS resilient rats (although a trend was found also in vulnerable animals), while its phosphorylation at $\mathrm{Ser}^{880}$ was higher in both CMS resilient and vulnerable rats, a change partially dampened by ketamine. In the hippocampus from all stressed groups, despite NMDA receptor expression levels were reduced in total extract, the levels of GluN2B-containing NMDA receptors were remarkably increased in synaptic membranes. Finally, mGlu2 underwent a selective downregulation in stress vulnerable animals, which was completely restored by acute ketamine.

Overall, these results are in line with a hypofunction of activity-dependent glutamatergic synaptic transmission induced by chronic stress exposure in all the animals, as suggested by the alterations of ionotropic glutamate receptors expression and localization at synaptic level. At the same time, the selective modulation of mGlu2 receptor, confirms its previously hypothesized functional role in regulating stress vulnerability and, for the first time here, suggests a mGlu2 involvement in the fast antidepressant effect of ketamine.
\end{abstract}

\section{Introduction}

The stress response is a physiological event, including biological and psychological processes activated in response to internal or external challenges or "stressors", that lead to the alteration of physiological homeostasis (Joels and Baram, 2009; Popoli et al., 2011; McEwen,
2013). The stress response is aimed at reaching a new equilibrium through adaptation, the so called "allostasis", allowing to activate coping strategies for survival. However, physical or psychological stress, especially when repeated, particularly intense, and affecting genetically susceptible subjects, is also recognized as main risk and precipitating factor for a number of systemic and neuropsychiatric

\footnotetext{
*Corresponding author at: Biology and Genetic Division, Department of Molecular and Translational Medicine, University of Brescia, Viale Europa 11, 25123 Brescia, Italy.

E-mail address: alessandro.barbon@unibs.it (A. Barbon).

${ }^{1}$ These authors equally contributed.

${ }^{2}$ Present Affiliation: School of Medicine and Surgery, University of Milano-Bicocca, Monza, Italy.
} 
disorders, including Major Depressive Disorder (MDD) (McEwen, 2017). Indeed, although everybody is exposed to stress throughout life, a high majority of people display resilience to stress and cope with it, while less than $20 \%$ of the individuals develop stress-related disorders (Del Giudice et al., 2011; Han and Nestler, 2017). In this context, one of the main issues in the study of the pathophysiology of stress-related disorders is the identification of molecular underpinnings of resilience and vulnerability to stress (Ozbay et al., 2008; Musazzi et al., 2017a).

Dysfunction of the glutamate system has been consistently shown to have a primary role in stress-related disorders and MDD (Sanacora et al., 2012; Duman et al., 2019). Neuroimaging studies have reported volumetric, functional, and connectivity alterations in cortico-limbic areas, including hippocampus (HPC), prefrontal cortex, and amygdala, where glutamatergic transmission predominates. On the other hand, preclinical evidence from stress-based animal models of depression has shown atrophy/remodeling of dendrites in the same brain regions affected in humans, suggesting that stress-induced maladaptive changes have a primary role in the chain of events precipitating or exacerbating MDD (Liu and Aghajanian, 2008; Popoli et al., 2011; McEwen et al., 2015; McEwen et al., 2016).

Many studies reported that both acute and chronic stress paradigms induce molecular and functional changes of ionotropic glutamate receptors (Yuen et al., 2009; Calabrese et al., 2012; Yuen et al., 2012; Kallarackal et al., 2013; Bonini et al., 2016). However, in our knowledge, no previous reports have explored a possible involvement of ionotropic glutamate receptors expression and localization in stress vulnerability, by assessing differences of glutamate receptors between stress-resilient and vulnerable animals. At the same time, changes in glutamate receptors RNA editing and splicing, which play a key role in regulating receptor localization and functional properties (Filippini et al., 2017), were never assessed in the context of chronic stress vulnerability/resilience.

Glutamate metabotropic receptors (mGlu) have also been involved in the regulation of the stress response (Peterlik et al., 2016). In particular, although conflicting results were obtained from different groups using different animal models of stress, mGlu2 levels were reported to be linked with stress vulnerability (Nasca et al., 2015; Highland et al., 2019), and antidepressant treatments were found to modulate mGlu2 expression (Morley-Fletcher et al., 2011; Bigio et al., 2016; Nasca et al., 2017; Zanos et al., 2019). Both positive and negative allosteric mGlu2 modulators are under development as putative new antidepressant drugs (O'Brien et al., 2018).

Recent studies reported that a single infusion of sub-anesthetic dose of ketamine, a non-competitive NMDA receptor antagonist, induces rapid and sustained antidepressant effect in treatment-resistant patients (Kraus et al., 2017; Lener et al., 2017; Kraus et al., 2019). In preclinical studies, ketamine was shown to rapidly reverse the dendritic retraction and spine loss induced by chronic stress in pyramidal neurons of prefrontal cortex and HPC (Anggono and Huganir, 2012; Moda-Sava et al., 2019; Tornese et al., 2019). It has also been demonstrated that the fast behavioral and synaptic actions of ketamine require enhancing $\alpha$ amino-3-hydroxy-5-methyl-4-isoxazolepropionic acid (AMPA) relative to $N$-methyl-D-aspartate (NMDA) receptor currents (Zanos et al., 2016; Kadriu et al., 2019). Finally, we have recently reported that both basal and depolarization-evoked presynaptic exocytotic glutamate release were significantly reduced in the HPC of Chronic Mild Stress (CMS) vulnerable rats, compared to controls and resilient animals (Tornese et al., 2019). Acute ketamine completely rescued basal glutamate release (a key regulator of homeostatic plasticity), but not depolarizationevoked release, in just $24 \mathrm{~h}$.

With this study, we aimed at identifying specific changes of AMPA, NMDA and mGlu receptor subunit expression and AMPA RNA editing and splicing, in the HPC of rats phenotypically resilient or vulnerable to the effects of CMS. We also assessed whether acute ketamine was able to dampen the alterations in CMS vulnerable animals.

\section{Material and methods}

\subsection{Animals}

Experiments were performed in accordance with the European Community Council Directive 2010/63/UE and approved by the Italian legislation on animal experimentation (Decreto Legislativo 26/2014, authorization N 308/2015-PR). A total of 47 male Sprague-Dawley 150$175 \mathrm{~g}$ rats (Charles River, Calco, Italy) were housed two per cage at $20-22{ }^{\circ} \mathrm{C}, 12 \mathrm{~h} \mathrm{light/dark}$ cycle (light on 7:00 a.m. off 7:00 p.m.), water and food ad libitum, except when required for CMS (Tornese et al., 2019).

\subsection{Sucrose preference test}

Sucrose preference test was performed as previously reported (Strekalova et al., 2011; Tornese et al., 2019). Two days before the start of CMS, sucrose habituation was performed exposing animals to two bottles containing 1\% sucrose solution, for $2 \mathrm{~h}$. Animals were subjected to sucrose preference test one day before the start of CMS (to assess baseline preference), after 3 and 5 weeks ( $1 \mathrm{~h}$ before sacrifice). Sucrose preference test consisted in presenting rats with two bottles, one containing $0.5 \%$ sucrose and one containing tap water, for $1 \mathrm{~h}$. The position of the bottles was inverted after $30 \mathrm{~min}$. The animals were not food and/or water deprived before the test, but only food deprived during sucrose exposure. Sucrose preference was calculated as: [sucrose solution intake $(\mathrm{ml}) /$ total fluid intake (ml)]x100]. After 3 weeks of CMS, sucrose preference test was used to divide stressed animals in CMS resilient (CMS-R) and vulnerable (CMS-V), applying a cut-off of preference at 55\% (Tornese et al., 2019).

\subsection{Chronic mild stress}

Rats were randomly divided in two experimental groups: control (CNT; non-stressed: $n=12$ ) and CMS (stressed: $n=35$ ) groups. CMS rats were subjected to mild, unavoidable and unpredictable stressors, including food/water deprivation (8-12 h), crowding (rats were randomly housed five per cage for 6-12 h), isolation (each rat was individually housed for 6-12 h), soiled cage (rats were housed in cages soiled with $500 \mathrm{ml}$ of water in the sawdust for 6-12 h), cage tilting (cages were tilted $45^{\circ}$ left or right for 6-12 h), light-on overnight, light/ dark reversal and forced swim (rats were forced to swim in $40 \mathrm{~cm}$ of room temperature water in a $30 \mathrm{~cm}$ in diameter Plexiglas cylinder, for 5 min once a week), for a total of 5 weeks (Willner, 2017; Tornese et al., 2019). Different stressors did not follow a predetermined order and were randomly performed along the five weeks of CMS, except for forced swim, which was never assigned before or after food/water deprivation and generally performed after soiled cage stress. Animals were subjected to stress at different time of the day and with a different length of time, in order to minimize prediction (Willner, 2017; Tornese et al., 2019).

CNT rats were left undisturbed, except for sucrose preference test, and kept in their home cages.

\subsection{Drug treatment}

After 4 weeks and 6 days of CMS, CMS-V rats were randomly divided into two groups: one was i.p. injected with a single sub-anesthetic dose of $10 \mathrm{mg} / \mathrm{kg}$ racemic ketamine (MSD Animal Health, Milan, Italy), while the other received physiological solution $(0.9 \% \mathrm{NaCl})$. CNT and CMS-R rats were also injected with physiological solution (Tornese et al., 2019). All the animals were subjected to sucrose preference test $23 \mathrm{~h}$ after treatment and sacrificed immediately after (after 5 weeks of CMS start and $24 \mathrm{~h}$ after treatment).

The HPC was immediately dissected on ice. Up to 10 animals/experimental group were randomly selected for further molecular studies. 
Left/right hippocampi were separated and randomly assigned to RNA extraction or homogenization and preparation of synaptic membranes.

\subsection{Corticosterone serum levels and adrenal glands weighing}

Serum corticosterone levels were measured as in (Musazzi et al., 2017b). Adrenal glands/total body weight ratio was calculated as: total weight of left and right adrenal glands (mg)/body weight (g) (Ieraci et al., 2016).

\subsection{RNA isolation and retro-transcription reaction}

Dissected HPC was immediately frozen in ethanol/dry ice bath and kept at $-80{ }^{\circ} \mathrm{C}$ until RNA extraction. $100 \mathrm{mg}$ of frozen HPC were added with $1 \mathrm{ml}$ of Tri-Reagent (Sigma-Aldrich, Milan, Italy), and homogenized with steel beads in a TissueLyser LT (Qiagen, Milan, Italy) at $50 \mathrm{~Hz}$ for $3^{\prime}$. Homogenized tissue was centrifuged in a 5415R MicroCentrifuge at $12,000 \mathrm{~g}$ for $10^{\prime}$ at $4{ }^{\circ} \mathrm{C}, 200 \mu \mathrm{l}$ chloroform were added to the RNA-containing supernatant and total RNA was extracted using Direct-zol RNA MiniPrep (Zymo Research, Freiburg, Germany), according to manufacturer instructions (Bonini et al., 2016; Ieraci et al., 2016). The concentration of the eluted RNA was measured on a NanoVue Plus Spectrophotometer (GE Healthcare Europe GmbH, Milano, Italy).

Reverse transcription was carried out using Moloney Murine Leukemia Virus-Reverse Transcriptase (MMLV-RT) (Thermo Fisher Scientific) for RNA editing and splicing analysis and iScript cDNA Reverse Transcription kit (BioRad Laboratories, Segrate, Italy) for realtime PCR experiments following manufactory instructions.

\subsection{Quantitative real-time PCR and RNA editing and splicing quantification}

qPCR was performed with Applied Biosystems 7500 or $7900 \mathrm{HT}$ Fast PCR Systems (Applied Biosystems, Monza, Italy), and TaqMan Universal PCR Master Mix (Applied Biosystems) or iTaq Universal SYBR Green supermix (BioRad Laboratories), as previously described (Russo et al., 2013; Tornese et al., 2019). TaqMan Gene Expression Assay id probes: GRIA1: Rn00709588_m1; GRIA2: Rn00568514_m1; GRIN1: RN01436038_m1; GRIN2A: Rn00561341_m1; GRIN2B: Rn00561352_m1 (Applied Biosystems); custom primers for SYBR Green: GRM2 fwd: TTCCCTCCTCAGTCTTCCACT, rev: TAGTTGACACC TTTTCGGCCT. The expression ratio of target genes in treated sample groups, compared to control group, was calculated using the $\Delta \Delta \mathrm{Ct}$ method. H2AFZ, GAPDH and PolII geometric mean was used as reference for TaqMan (ID H2AFZ Taqman probe: Rn00821133_g1; ID GAPDH: Rn99999916_m1; ID PolII: Rn00580118_m1), while the geometric mean of PO and SD18 was used for SYBR Green (PO fwd primer: AGTCGGAGGAATCCGATGAG, rev primer: ATTAAGCAGGCTGACTTG GTG; SD18 fwd primer: CATGCAGAACCCACGACAAT, rev primer: CTTCCCATCCTTCACGTCCT). Each individual determination was repeated in triplicate (Russo et al., 2013; Tornese et al., 2019).

The quantification for AMPA receptor subunits GRIA2 Q/R and GRIA2, GRIA3 and GRIA4 R/G editing levels was measured by sequence analysis as previously described (Izzi et al., 2002; Orlandi et al., 2011; La Via et al., 2013; Bonini et al., 2015, 2016).

Briefly, in the electropherogram obtained after RT-PCR and sequencing analysis of a pool of transcripts that might be edited or not, the nucleotide that undergoes the editing reaction appears as 2 overlapping peaks: A from unedited transcripts, and $\mathrm{G}$ from the edited ones. The editing level can be reliably calculated as a function of the ratio between the G peak area and A plus G peaks areas. The areas representing the amount of each nucleotide were quantified using Discovery Studio (DS) Gene 1.5 (Accelrys Inc., San Diego, CA, USA), and the means and standard errors for each experimental group were calculated and used for subsequent statistical analysis.
The levels of the flip/flop splicing variants were evaluated by sequence analysis as described previously (Barbon et al., 2010). For each of the AMPA receptor subunits, both isoforms were amplified using a pair of common primers. The amplification products, consisting of both flip and flop isoforms at different concentrations were sequenced; the flip and flop exons appeared as peaks superimposed in the electropherogram. Flip and flop exons exhibit mismatches of $A / G$ in specific locations. The relative expression level of the flip exon can thus be reliably calculated as the ratio of the peak area of $G$ (flip) and the sum of the peak areas $A+G$ in different positions. The areas representing the amount of each nucleotide were quantified using DS-Gene 1.5 (Accelrys Inc., San Diego, CA, USA), and the means and standard errors for each experimental group were calculated and used for subsequent statistical analysis.

\subsection{Preparation of homogenates and purified synaptic membranes}

HPC were homogenized in $0.32 \mathrm{M}$ ice-cold sucrose containing TRIS $0.01 \mathrm{M}, 0.1 \mathrm{mM}$ EGTA, $2 \mathrm{ul} / \mathrm{ml}$ protease inhibitors (Sigma-Aldrich), phosphatase inhibitor cocktail (Thermo FisherScientific, Milan, Italy), $\mathrm{pH}$ 7.4. $200 \mu \mathrm{l}$ of homogenate were aliquoted and immediately frozen.

Purified synaptic terminals (synaptosomes) were freshly obtained by centrifugation on discontinuous Percoll gradients as previously reported (Treccani et al., 2014). For the preparation of synaptic membranes, synaptosomes were resuspended in lysis buffer: $120 \mathrm{mM} \mathrm{NaCl}$, 20 mM HEPES pH 7.4, 0.1 mM EGTA, 0.1 mM DTT, containing $2 \mathrm{ul} / \mathrm{ml}$ protease inhibitors (Sigma-Aldrich) and phosphatase inhibitor cocktail (Thermo FisherScientific), pH 7.4. The synaptic membrane fraction was obtained by centrifugation at 29,000 $\mathrm{g}$ for $30^{\prime}$ at $4{ }^{\circ} \mathrm{C}$ as described previously (Musazzi et al., 2010) and stored at $-80{ }^{\circ} \mathrm{C}$.

\subsection{Western blotting}

The BCA protein concentration assay (Sigma-Aldrich, St. Louis, MO, USA) was used for protein quantitation. Western blotting analysis was carried out as previously described by incubating PVDF or nitrocellulose membranes ( $\mathrm{GE}$ Healthcare Europe $\mathrm{GmbH}$ ), containing electrophoresed and blotted proteins from either homogenates or presynaptic membranes (Bonini et al., 2016; Musazzi et al., 2017b), with antibodies for total GluA1 (1:200, cod. AGC004, Alomone Labs, Gerusalem, Israel), phosphoSer831-GluA1 (1:1000, cod. Ab109464, Abcam, Milano, Italy), phosphoSer ${ }^{845}$-GluA1 (1:1000, cod. ab3901 Abcam), GluA2 (1:2500, cod. AGC005, Alomone), phosphoSer ${ }^{880}$ GluA2 (1:1.000, cod. Ab52180, Abcam), GluN1 (1:500, cod. AB9864, Merck Millipore, Milano, Italy), GluN2A (1:500, AB1555P, Merck Millipore), GluN2B (1:500, cod. 454,582, Calbiochem-Merck Millipore), mGlu1 (1:1000, cod. Ab82211, Abcam), mGlu2 (1:1000, cod. Ab106811, Abcam), mGlu5 (1:1000, cod. Ab76316, Abcam). Mouse monoclonal anti-GAPDH (1:40.000, cod. Mab374, Millipore) or rabbit monoclonal anti- $\beta$-Actin (1:3000, cod.04-1116, Millipore) were used as internal controls.

Luminescence or chemiluminescence were used for signal detection. Membranes incubated with secondary horseradish peroxidase-conjugated antibodies were detected with a chemiluminescent solution: ECL Star Enhanced (Euroclone, Milano, Italy) or Clarity (Bio-Rad Laboratories). For detection of luminescent signal, the membranes were incubated for $1 \mathrm{~h}$ at RT with anti-rabbit secondary antibody (IR-Dye, LICOR Biosciences, Lincoln, NE, USA cod: 926-32,211) or anti-mouse secondary antibody (IR-Dye cod:926-68,020), both diluted 1:2000 in TBS-T. Signals were detected using an Odyssey infrared imaging system (LI-COR Biosciences) and quantified using Odyssey version 1.1 (LI-COR Biosciences).

QuantityOne analysis software (Bio-Rad Laboratories), Image-Pro Plus and Image Studio software (LI-COR Biosciences) were used for quantification (Bonini et al., 2016; Musazzi et al., 2017b).

Data are presented as optical density ratios of the investigated 
protein band normalized on GAPDH or $\beta$-Actin bands in the same line and are expressed as percentage of controls. The levels of GluA phosphorylated subunits were normalized to respective total GluA levels (Bonini et al., 2016).

\subsection{Data analysis}

All the analyses were carried out in individual animals (independent determinations).

For sucrose preference test on CNT and CMS rats 3 weeks after CMS start, unpaired two-tailed Student $t$-test was used. For all the other experiments, One-Way ANOVA followed by Tukey's post-hoc test was used. ANOVA F and $p$ values are reported in "Results" section, while the $\mathrm{p}$ values of post-hoc tests are reported in figure legends. NMDA, AMPA and mGluR receptor subunits were analyzed in independent experiments and no multiple correction was performed. Phosphorylation levels were normalized on total subunit expression.

Data were expressed as means \pm standard error of the mean (SEM). Statistical analysis was carried out using GraphPad Prism 8 (GraphPad Software, La Jolla, CA, USA).

\section{Results}

3.1. Ketamine reversed anhedonic behavior but did not reduce the levels of corticosterone in vulnerable animals

Sucrose preference test was applied to assess the anhedonic phenotype of all the animals (Tornese et al., 2019). The test was applied before the start of CMS (to verify that all the animals showed preference for sucrose: mean $72.11 \% \pm 1.77$ ), then after 3 weeks (to separate the animals in stress-resilient and vulnerable), and just before sacrifice (after 5 weeks of CMS, $24 \mathrm{~h}$ after $10 \mathrm{mg} / \mathrm{kg}$ ketamine injection) (see methods for more details).

After 3 weeks of CMS, sucrose preference was significantly reduced in stressed animals (Fig. 1A; unpaired t-test, $t=3.454, p<.01$ ), however, applying a cut-off at $55 \%$ of sucrose preference, rats were deemed resilient to CMS (CMS-R) (preference for sucrose higher than $55 \%$ ), or vulnerable (CMS-V) (preference lower than 55\%) (Fig. 1B; One-Way ANOVA, $\left.\mathrm{F}_{(2,47)}=38,93 p<.001\right)$. After 5 weeks of CMS, half of CMS-V were injected with ketamine (CMS-V + KET) (Tornese et al., 2019), and sucrose preference test was repeated $24 \mathrm{~h}$ later (Fig. 1C). Ketamine completely restored the anhedonic phenotype (One-Way ANOVA, $\mathrm{F}_{(3,43)}=25,83 \mathrm{p}<.001$ )

CMS was found to increase the circulating levels of corticosterone in CMS-V (no significant increase in CMS-R), while ketamine had no effects at this level (Fig. 1D; One-Way ANOVA $\mathrm{F}_{(3,44)}=14,19$, $\mathrm{p}<.001$ ). Although a trend towards increasing adrenal glands weight was observed in stressed animals, no statistically significant changes were observed (Fig. 1E; One-Way ANOVA $\mathrm{F}_{(3,43)}=1,91, p>.05$ ).

\subsection{CMS and ketamine had no effect on ionotropic glutamate receptors} mRNA expression or on AMPA subunits RNA editing and splicing levels in $H P C$

To assess whether CMS and acute ketamine may affect glutamate receptors in the HPC, we first measured mRNA expression levels of the main AMPA and NMDA receptor subunits. No statistically significant differences were found in any of the analyzed mRNAs (Table 1, OneWay ANOVA, $\mathrm{p}>$.05).

Moreover, no changes were induced by CMS or KET treatment in the editing levels at the R/G sites or in the flip/flop RNA splicing ratio of all AMPA receptor subunits tested (Table 2, One-Way ANOVA, $\mathrm{p}>.05$ ).
3.3. Modulation of ionotropic glutamate receptor subunits expression and phosphorylation levels induced by CMS and ketamine in HPC

Western blot analyses for AMPA and NMDA receptor subunits were performed on total cell homogenate and purified synaptic membranes from HPC of CNT, CMS-R, CMS-V and CMS-V + KET, to assess changes in protein expression/phosphorylation.

Considering AMPA receptors, in total homogenate, no significant alterations were measured among experimental groups, despite some inter-individual variations especially in GluA1 phosphorylation (Fig. 2; One-Way ANOVA, $\left.\mathrm{F}_{(3,18)}=0,95 p>.05\right)$. On the other hand, at synaptic level, while no changes were found in GluA1 (Fig. 3A-C; OneWay ANOVA $\left.\mathrm{F}_{(3,26)}=1,12, \mathrm{p}>.05\right)$, GluA2 total expression and phosphorylation at Ser $^{880}$ were significantly modulated by CMS (Fig. 3D, E). A marked increase of GluA2 levels at synaptic membranes was measured after CMS exposure, although significance was reached only for CMS-R group (Fig. 3D; One-Way ANOVA $\mathrm{F}_{(3,24)}=5,05$, $p<.01)$. GluA2 phosphorylation at $\operatorname{Ser}^{880}$, known to promote subunit internalization (Anggono and Huganir, 2012), was instead significantly increased in HPC synaptic membranes from both CMS-R and CMS-V, while the levels in CMS-V + KET animals were not different from controls, suggesting that ketamine may partly dampen the increase of $\mathrm{p}$ $\mathrm{Ser}^{880}$-GluA2 induced by CMS (Fig. 3E; One-Way ANOVA $\left.\mathrm{F}_{(3,21)}=5,68, \mathrm{p}<.01\right)$.

CMS remarkably affected NMDA receptor subunits expression levels, both in total homogenate and synaptic membranes (Figs. 4 and 5). In total extract, GluN1 levels were significantly reduced in all stressed animals (independently on stress vulnerability and drug treatment) (Fig. 4A; One-Way ANOVA, $\mathrm{F}_{(3,15)}=9,47, p<.001$ ). At the same time, both GluN2A and GluN2B expression showed a clear trend for reduction after CMS, although significance was reached only in CMS-R for GluN2A (Fig. 4B; One-Way ANOVA, $\mathrm{F}_{(3,15)}=4,62, p<.05$ ), and in CMS-V and CMS-V + KET for GluN2B (Fig. 4C; One-Way ANOVA $\left.\mathrm{F}_{(3,18)}=4,86, \mathrm{p}<.05\right)$. We also measured GluN2A/GluN2B ratio, which is considered a key factor in regulating glutamate synapses activity (Yashiro and Philpot, 2008), and found no significant changes in total homogenate, despite a trend towards increase in CMS-V + KET rats (Fig. 4D; One-Way ANOVA $\mathrm{F}_{(3,14)}=2,04, p>.05$ ).

A completely different pattern was revealed in HPC synaptic membranes. Indeed, opposite to what observed in the cell lysate, GluN1 levels were remarkably increased in all stressed animals (Fig. 5A; OneWay ANOVA $\left.\mathrm{F}_{(3,22)}=4,08, \mathrm{p}<.05\right)$. No significant alterations were found in GluN2A (Fig. 5B; One-Way ANOVA $\mathrm{F}_{(3,25)}=0,29, \mathrm{p}>.05$ ) and GluN2B (Fig. 5C; One-Way ANOVA $\mathrm{F}_{(3,25)}=1,80, \mathrm{p}>.05$ ), although GluN2B showed an increasing trend in all CMS rats. Consequently, GluN2A/GluN2B ratio was significantly decreased in HPC synaptic membranes of all stressed groups (Fig. 5D; One-Way ANOVA $\left.\mathrm{F}_{(3,18)}=4,68, \mathrm{p}<.05\right)$.

3.4. Modulation of metabotropic glutamate receptor subunits expression levels induced by CMS and ketamine in HPC

To assess whether CMS and ketamine were able to modulate mGlu receptor levels, we measured their expression in HPC total homogenate and purified synaptic membranes from all the experimental groups. The analysis was limited to the most expressed and characterized mGlu receptors: mGlu1, mGlu2 and mGlu5 (Ferraguti and Shigemoto, 2006) (Fig. 6).

No alterations were measured for mGlu1 and mGlu5, both for total expression and at synaptic level (Fig. 6A,D for mGlu1 One-Way ANOVA $\mathrm{F}_{(3,49)}=0,68, \mathrm{~F}_{(3,29)}=1,03, \mathrm{p}>.05$; Fig. 6C,F for mGlu5; One-Way ANOVA $\left.\mathrm{F}_{(3,40)}=1,53, \mathrm{~F}_{(3,30)}=2,18, \mathrm{p}>.05\right)$. On the other hand, mGlu2 expression was significantly reduced in HPC homogenate and synaptic membranes, selectively in CMS-V rats, while acute ketamine completely restored this reduction (Fig. 6B: homogenate, One-Way ANOVA $\mathrm{F}_{(3,49)}=3,78, \mathrm{p}<.05$; Fig. $6 \mathrm{E}$ : synaptic membranes, One- 
A

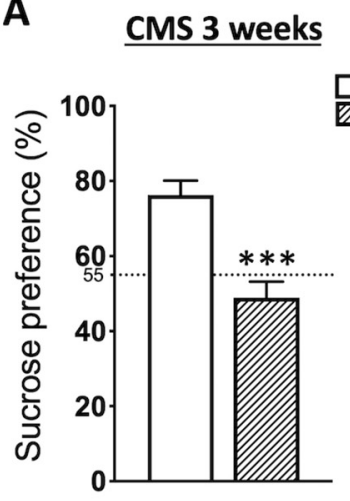

B

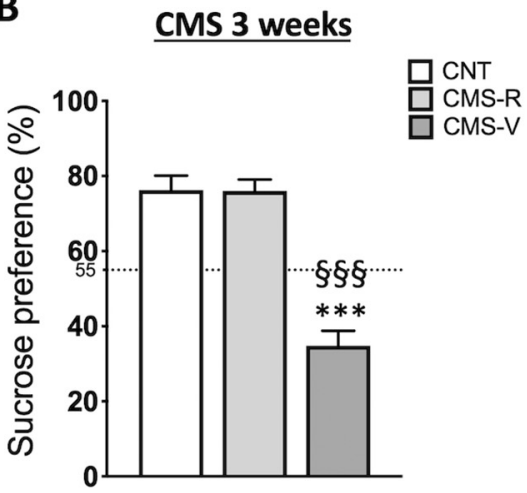

C

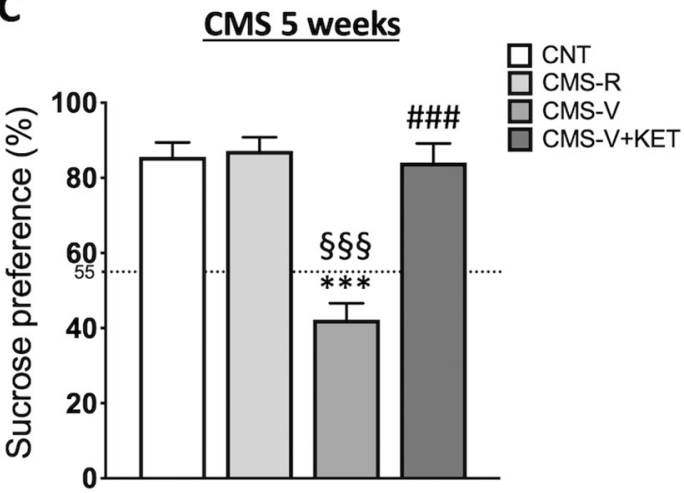

D

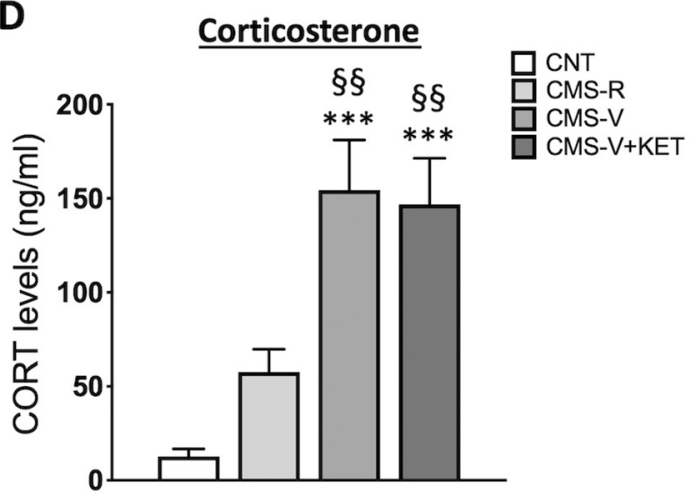

E

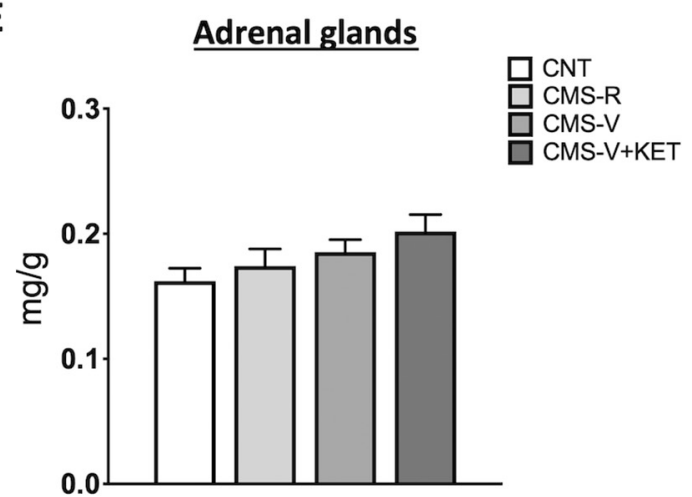

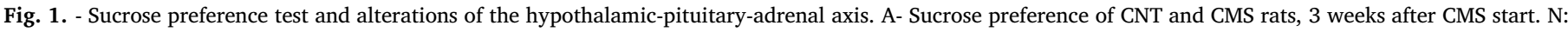

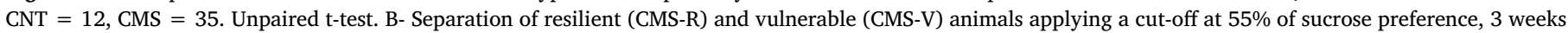

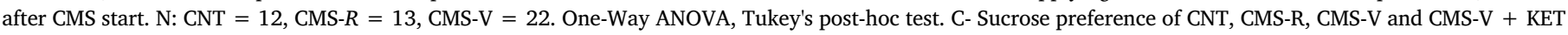

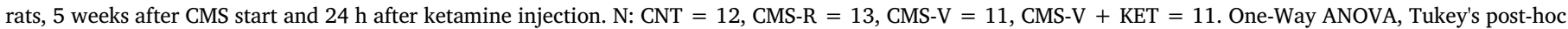

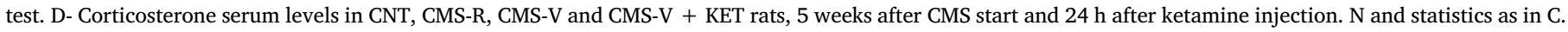

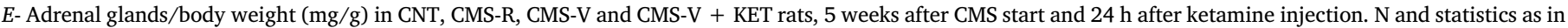
C. Data are shown as means + SEM. ${ }^{* * *} p<.001$ vs CNT; $\S \S p<.01$, $\S \S \S \mathrm{p}<.001$ vs CMS-R; \#\#\# p $<.001$ vs CMS-V.

Way ANOVA $\left.\mathrm{F}_{(3,29)}=5,56, p<.01\right)$. This was not dependent on modulation of mRNA expression $\left(\log _{2}{ }^{-\Delta \Delta \text { ct }}\right.$ : CNT $0.000 \pm 0.030$, CMS$\mathrm{R}-0.044 \pm 0.064$, CMS-V $0.036 \pm 0.048$, CMS-V + KET $0.0855 \pm 0.067, N=10$; One-Way ANOVA, $\mathrm{p}>.05$ ).

\section{Discussion}

In this study we used the classical CMS model of depression in rats (Willner, 2017; Tornese et al., 2019) to investigate the modifications induced by chronic stress and acute ketamine injection on AMPA/ NMDA ionotropic and metabotropic glutamate receptors at the transcriptional, post transcriptional and translational level. In particular, we assessed their modifications in the HPC of rats phenotypically resilient or vulnerable to CMS and in CMS vulnerable animals treated with antidepressant dose of ketamine $(10 \mathrm{mg} / \mathrm{kg}) 24 \mathrm{~h}$ before sacrifice.

The separation of animals in resilient and vulnerable to CMS was performed using the sucrose preference test (Tornese et al., 2019). To assess changes in the activation of the hypothalamic-pituitary-adrenal axis, we measured corticosterone serum levels and adrenal glands weight, finding, as previously reported, a marked increase in corticosterone serum levels in CMS vulnerable rats, which were not modulated by acute ketamine. However, differently from our previous report (Tornese et al., 2019), we did not measure any significant change of corticosterone in CMS resilient animals, nor of adrenal glands weight, in any of the experimental groups. The lack of significance could be due to the lower number of animals used here $(N=11-13)$, compared with the previous study $(N=21-54)$.

Although chronic stress and ketamine had no effect on ionotropic glutamate receptors mRNAs (expression, editing and splicing), we found selective modulations in their protein expression, phosphorylation and localization at synaptic membranes in HPC.

Table 1

- qPCR analysis of ionotropic glutamate receptor coding mRNAs. Expression levels of GRIA1, GRIA2, GRIA3, GRIA4 and GRIN1, GRIN2A, GRIN2B mRNA by qPCR. Data are reported as $\log _{2}{ }^{-\Delta \Delta \mathrm{ct}}$ (expression level of control sample is equal to 0 ) and as means \pm SEM $(N=8-10)$. One-Way ANOVA $p>.05$.

\begin{tabular}{|c|c|c|c|c|c|}
\hline & CNT & CMS-R & CMS-V & CMS-V + KET & ANOVA \\
\hline GRIA1 & $0.002 \pm 0.102$ & $-0.031 \pm 0.059$ & $-0.171 \pm 0.097$ & $-0.125 \pm 0.096$ & $\mathrm{~F}_{(3,32)}=1,03$ \\
\hline GRIA2 & $0.001 \pm 0.786$ & $-0.058 \pm 0.096$ & $-0.074 \pm 0.205$ & $0.037 \pm 0.088$ & $\mathrm{~F}_{(3,30)}=3,79$ \\
\hline GRIA3 & $0.000 \pm 0.080$ & $-0.128 \pm 0.106$ & $-0.287 \pm 0.128$ & $-0.134 \pm 0.095$ & $\mathrm{~F}_{(3,32)}=0,76$ \\
\hline GRIA4 & $0.002 \pm 0.041$ & $-0.180 \pm 0.064$ & $-0.246 \pm 0.110$ & $-0.150 \pm 0.101$ & $\mathrm{~F}_{(3,32)}=1,35$ \\
\hline GRIN1 & $0.001 \pm 0.500$ & $-0.082 \pm 0.056$ & $-0.187 \pm 0.070$ & $-0.181 \pm 0.156$ & $\mathrm{~F}_{(3,34)}=0,81$ \\
\hline GRIN2A & $0.001 \pm 0.110$ & $0.036 \pm 0.185$ & $-0.284 \pm 0.202$ & $-0.143 \pm 0.104$ & $\mathrm{~F}_{(3,32)}=1,61$ \\
\hline GRIN2B & $0.000 \pm 0.079$ & $-0.102 \pm 0.079$ & $-0.210 \pm 0.111$ & $-0.164 \pm 0.114$ & $\mathrm{~F}_{(3,36)}=1,91$ \\
\hline
\end{tabular}


Table 2

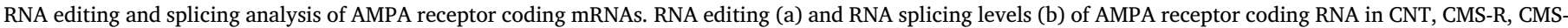
$\mathrm{V}, \mathrm{CMS}-\mathrm{V}+\mathrm{KET}$ rats. Data are expressed as percentage and as means \pm SEM $(N=5)$. One-Way ANOVA p $>.05$.

\begin{tabular}{|c|c|c|c|c|c|}
\hline & CNT & CMS-R & CMS-V & CMS-V + KET & ANOVA \\
\hline \multicolumn{6}{|l|}{ a. RNA editing } \\
\hline GRIA2 R/G & $48.9 \pm 1.6$ & $50.1 \pm 0.9$ & $45.9 \pm 1.1$ & $49.6 \pm 0.6$ & $\mathrm{~F}_{(3,16)}=0,06$ \\
\hline GRIA2 Q/R & $100 \pm 0.0$ & $100 \pm 0.0$ & $100 \pm 0.0$ & $100 \pm 0.0$ & $\mathrm{~F}_{(3,16)}=0,00$ \\
\hline GRIA3 R/G & $88.5 \pm 0.6$ & $89.2 \pm 0.6$ & $89.5 \pm 1.0$ & $90.6 \pm 1.6$ & $\mathrm{~F}_{(3,16)}=0,55$ \\
\hline GRIA4 R/G & $53.4 \pm 1.6$ & $54.3 \pm 1.0$ & $53.0 \pm 0.7$ & $53.1 \pm 1.5$ & $\mathrm{~F}_{(3,16)}=0,87$ \\
\hline \multicolumn{6}{|l|}{ b. RNA splicing } \\
\hline GRIA2 flip/flop & $44.3 \pm 0.7$ & $44.5 \pm 1.1$ & $43.1 \pm 1.2$ & $46.6 \pm 1.2$ & $\mathrm{~F}_{(3,16)}=1,47$ \\
\hline GRIA3 flip/flop & $69.9 \pm 0.7$ & $69.4 \pm 1.4$ & $69.8 \pm 0.4$ & $71.2 \pm 0.8$ & $\mathrm{~F}_{(3,16)}=0,80$ \\
\hline GRIA4 flip/flop & $37.9 \pm 1.5$ & $40.0 \pm 1.0$ & $40.9 \pm 2.4$ & $42.1 \pm 1.1$ & $\mathrm{~F}_{(3,16)}=0,33$ \\
\hline
\end{tabular}

A

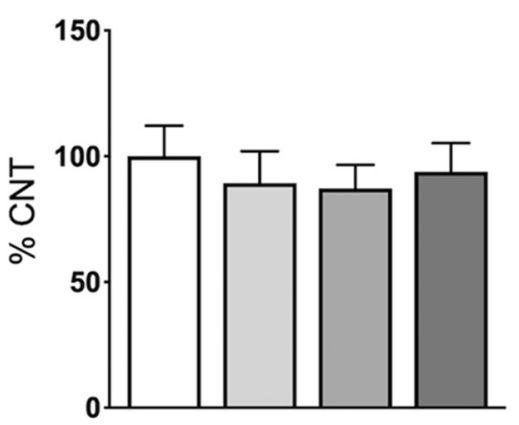

D

GluA2

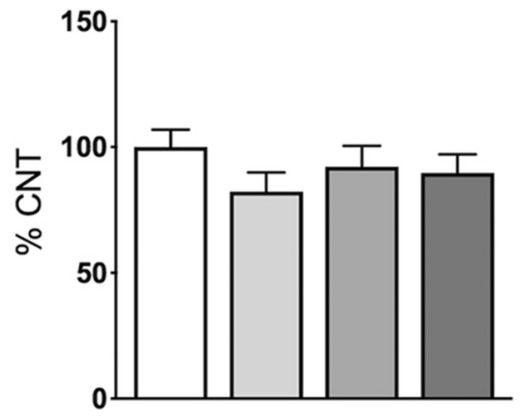

B

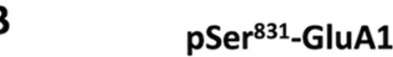

C
pSer ${ }^{845}$-GluA1

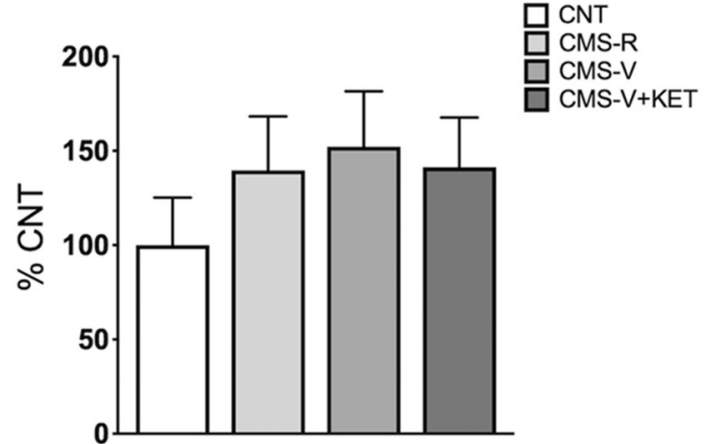

E

pSer $880-G l u A 2$

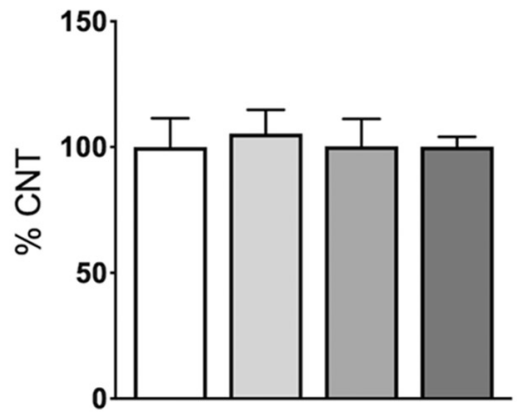

Fig. 2. - Protein expression levels and phosphorylation of AMPA receptor subunits in homogenate from HPC. A- Total GluA1, B- GluA1 phospho-Ser ${ }^{831}$, C- GluA1 phospho-Ser ${ }^{845}$, D- Total GluA2, E- GluA2 phospho-Ser ${ }^{880}$, in HPC total homogenate from CNT, CMS-R, CMS-V and CMS-V + KET rats. Data are expressed as percentage of controls, and shown as means + SEM. $\mathrm{N}=8-10$.

\subsection{AMPA receptors}

Considering AMPA receptors, we focused on GluA1 and GluA2 subunits, the most highly expressed in the HPC of the adult brain (Anggono and Huganir, 2012), and on their phosphorylation state, modulating receptor activity and localization. In particular, we measured phosphorylation of GluA1 at $\operatorname{Ser}^{831}$ and $\operatorname{Ser}^{845}$, respectively known for enhancing channel conductance, and for increasing opening probability and pick amplitude of AMPA receptor currents, and phosphorylation of GluA2 at $\operatorname{Ser}^{880}$, which promotes AMPA receptor internalization (Lu and Roche, 2012; Wang et al., 2014).

We found no changes in GluA1 expression and phosphorylation either in the total extract, or at synaptic membranes. On the other hand, although GluA2 levels did not show any alterations in HPC homogenate, GluA2 synaptic expression was significantly increased only in CMS resilient rats (although a trend was found also in vulnerable animals), while its phosphorylation at $\operatorname{Ser}^{880}$ was found augmented both in CMS resilient and vulnerable rats. Interestingly, considering that GluA2 phosphorylation at $\operatorname{Ser}^{880}$ in CMS vulnerable rats treated with ketamine was not different from controls, this may suggest that the drug attenuated the increase of phosphorylation induced by stress.

Since the constitutive editing of the GluA2 subunit makes AMPA channels impermeable to $\mathrm{Ca}^{2+}$, and leads to a relatively low conductance compared to GluA1-containing receptors, an increase of GluA2 at synaptic membrane suggests a stress-induced reduction of AMPA-mediated synaptic currents (Filippini et al., 2017). However, the concomitant increase of GluA2 phosphorylation at $\mathrm{Ser}^{880}$ in both resilient and vulnerable animals suggests a possible cellular response attempting at increasing the internalization of GluA2-containing AMPA receptors. On the other hand, the lack of changes in GluA2 synaptic levels and phosphorylation in the HPC of vulnerable animals treated with ketamine, compared to controls, suggests a possible stabilization 
A

GluA1

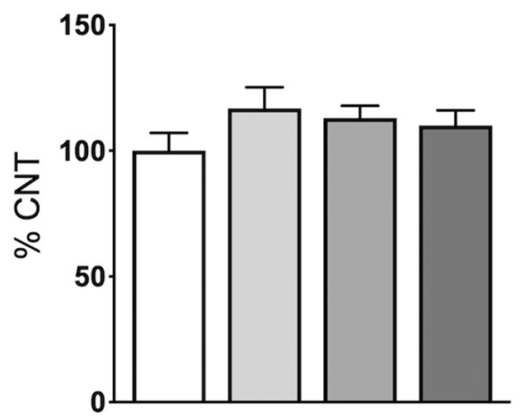

D

GluA2

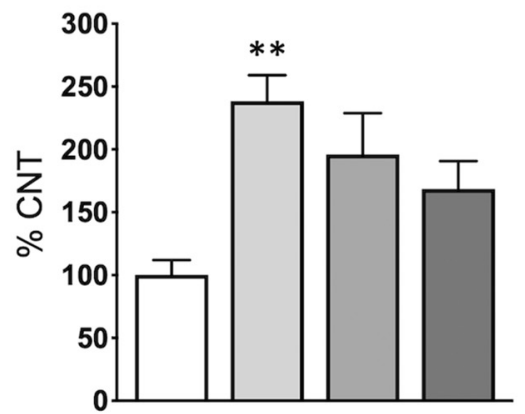

B

pSer ${ }^{831}$-GluA1

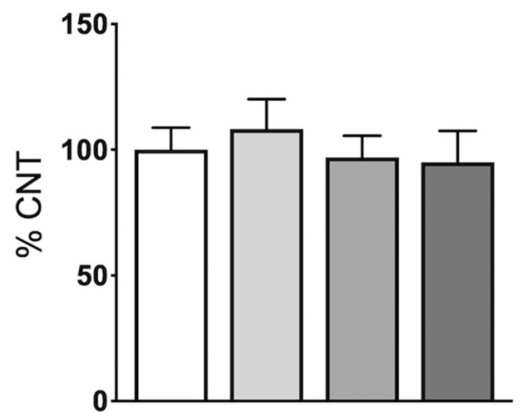

E
C

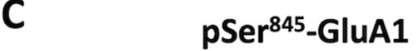

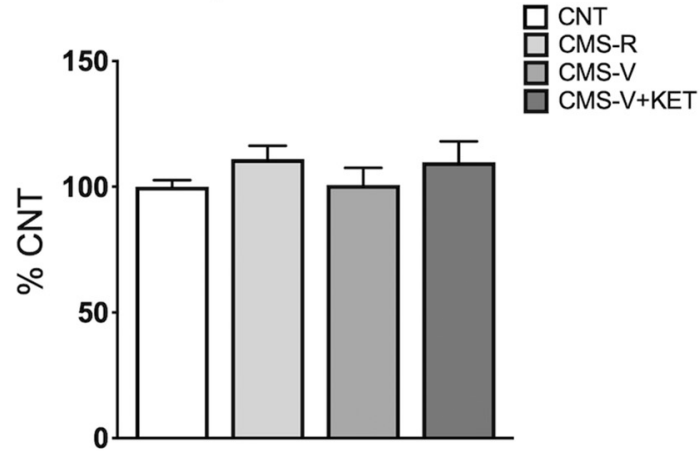

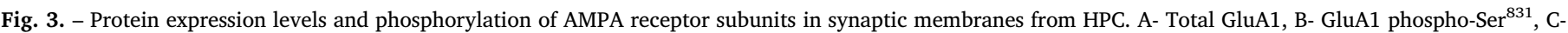

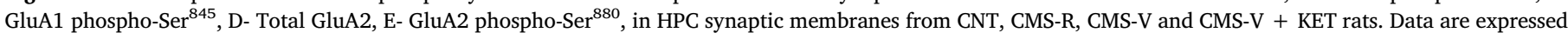
as percentage of controls and shown as means + SEM. N $=8-10$; Tukey's post-hoc test* $p<.05, * * p<.01$ vs CNT.

A

GluN1

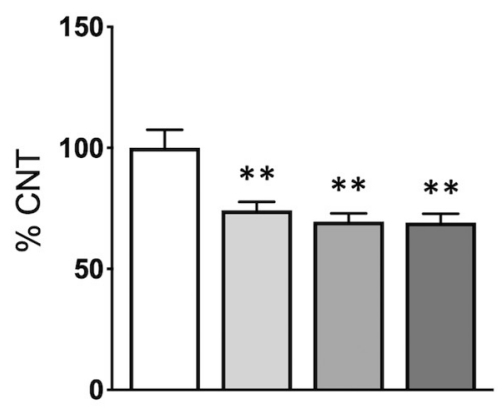

C

GluN2B

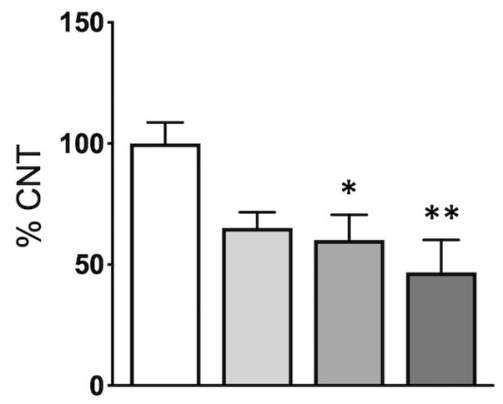

B

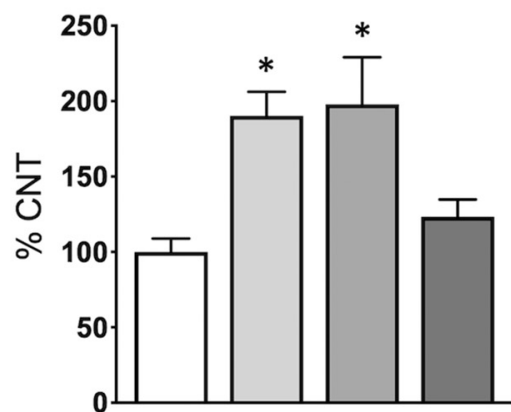

Fig. 4. - Protein expression levels of NMDA receptor subunits in homogenate from HPC. A- Total GluN1, B- Total GluN2A, C- Total GluN2B, D- GluN2A/ GluN2B ratio, in HPC total homogenate from CNT, CMS-R, CMS-V and CMS-V + KET rats. Data are expressed as percentage of controls and shown as means + SEM. N = 8-10;. Tukey's post-hoc test * $\mathrm{p}<.05, * * \mathrm{p}<.01$ vs CNT. 
A

GluN1

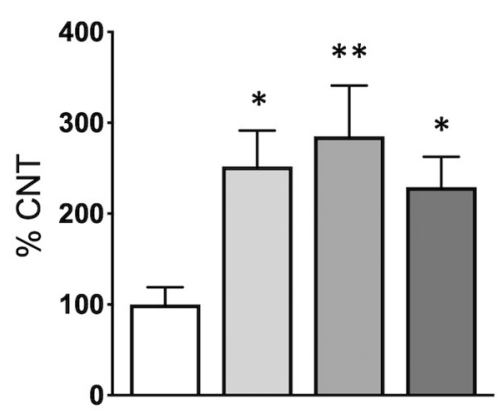

C

GluN2B

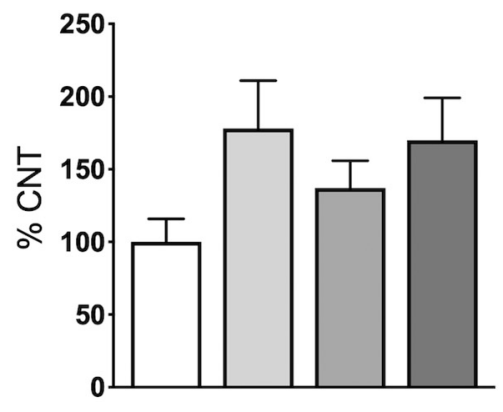

B

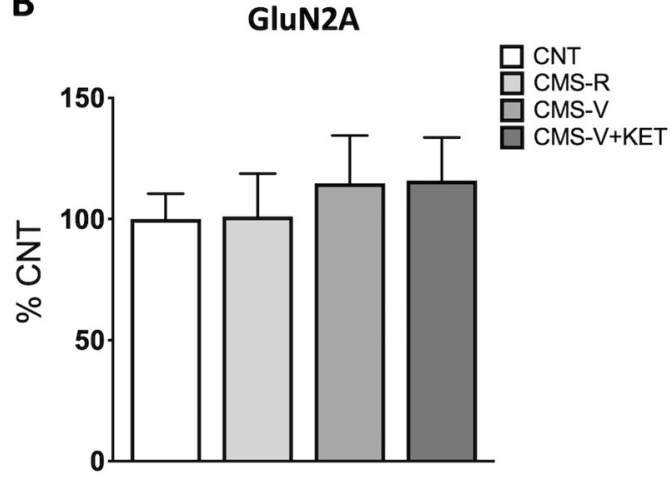

D
Fig. 5. - Protein expression levels of NMDA receptor subunits in synaptic membranes from HPC. A- Total GluN1, B- Total GluN2A, C- Total GluN2B, DGluN2A/GluN2B ratio, in HPC synaptic membranes from CNT, CMS-R, CMS-V and CMS-V + KET rats. Data are expressed as percentage of controls and shown as means + SEM. N = 8-10; Tukey's post-hoc test $* \mathrm{p}<.05, * * \mathrm{p}<.01$ vs CNT.

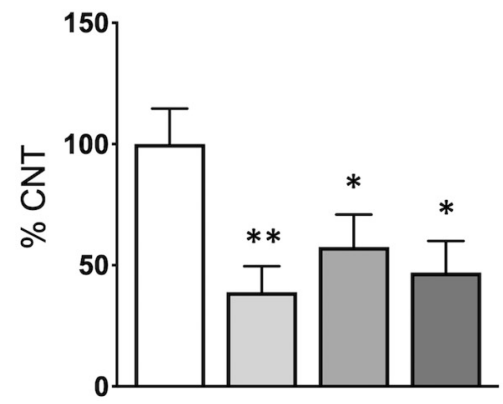

A

mGlu1 (HOMO)

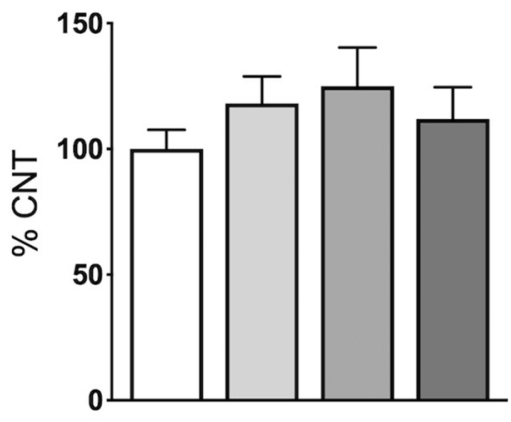

D mGlu1 (SYN MEMBR)

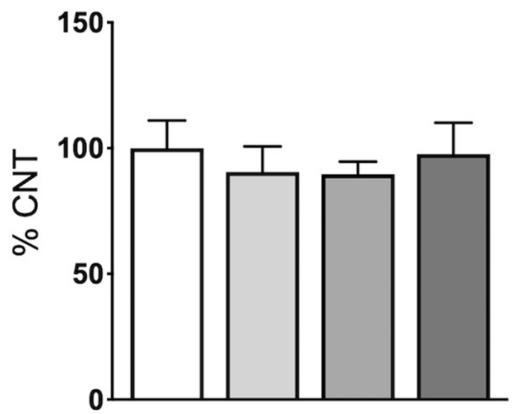

B<smiles>[B]CCCCCOC</smiles>

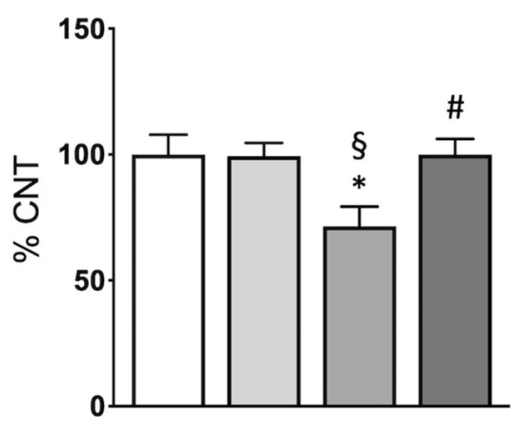

E
C mGlu5 (HOMо)

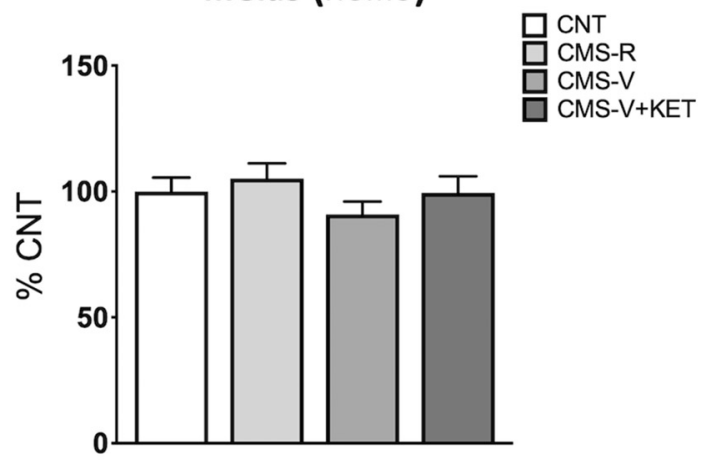

$\mathbf{F}$

mGlu5 (SYN MEMBR)
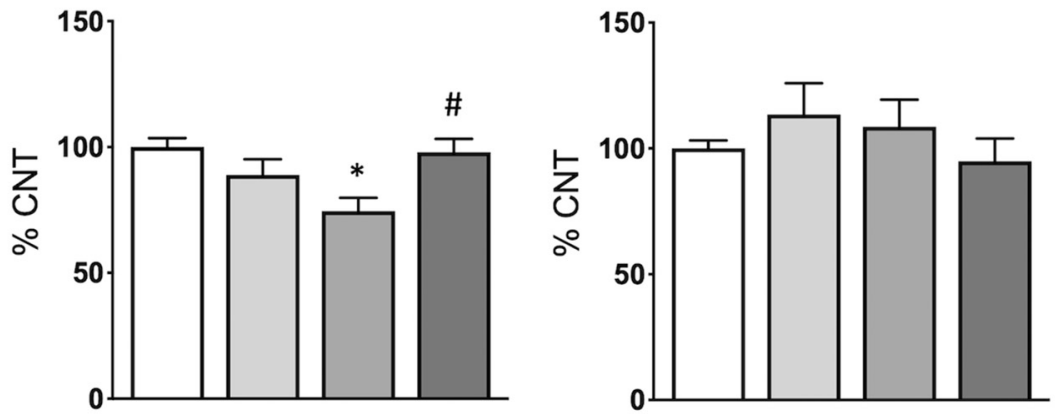

Fig. 6. - Protein expression levels of mGlu receptor subunits in homogenate and synaptic membranes from HPC. A- Total mGlu1, B- Total mGlu2, C- Total mGlu5, in HPC total homogenate from CNT, CMS-R, CMS-V and CMS-V + KET rats. D- Total mGlu1, E- Total mGlu2, F- Total mGlu5, in HPC synaptic membranes from CNT, CMS-R, CMS-V and CMS-V + KET rats. Data are expressed as percentage of controls and shown as means + SEM. N $=8-10$; Tukey's post-hoc test * $\mathrm{p}<.05$ vs CNT; $\S \mathrm{p}<.05$ vs CMS-R; \# $\mathrm{p}<.05$ vs CMS-V. 
of AMPA receptor functional properties induced by the drug.

A previous study reported increased protein expression of total GluA2 in the HPC after five weeks of chronic unpredictable mild stress (Li et al., 2011). Although partly in contrast with our results, showing changes only at synaptic compartment, both works sugget an involvement of GluA2 in the cellular response to chronic stress.

\subsection{NMDA receptors}

We also found modifications in NMDA receptor subunits total expression levels and synaptic membrane localization, induced in the HPC by CMS and ketamine treatment.

NMDA receptors are tetramers composed of two constitutive GluN1 subunits, forming the channel pore, and mainly GluN2A or GluN2B subunits; the precise combination of subunits determines the functional properties of the receptor (Sanz-Clemente et al., 2013). It is well known that NMDA receptor subunit composition changes during development: while GluN2B is abundant in the early postnatal brain, the level of GluN2A, characterized by faster rising and decay kinetics, increases progressively during development (Lohmann and Kessels, 2014). In the adult brain, GluN2A is enriched at synaptic sites, while GluN2B is mainly extrasynaptic (Bellone and Nicoll, 2007), and the GluN2A/ GluN2B ratio was shown to be regulated in response to changes of neuronal activity (Yashiro and Philpot, 2008). In particular, it was demonstrated that increased GluN2A/GluN2B ratio is related with increased synaptic stimulation and transmission, and that its dynamic regulation is a major determinant of synaptic plasticity (Malenka and Bear, 2004).

In HPC total extract, a marked reduction of the expression levels of GluN1 in all stressed animals was observed, that was not reversed by ketamine treatment. A similar reduction was also measured in GluN2A and GluN2B subunits expression, although significance was respectively reached only in resilient and in vulnerable rats (independently on ketamine treatment). No significant changes were instead observed for GluN2A/2B ratio, although high variability was noticed in vulnerable animals treated with ketamine, suggesting individual molecular differences in drug response at this level. Unfortunately, the available number of animals did not allow possible correlation with the behavioral antidepressant response.

Intriguingly, a completely different pattern was found in the synaptic membrane fraction. Here, a remarkable increase of GluN1 levels was measured in all stressed rats (independently on stress vulnerability or drug treatment), together with no changes in GluN2A and a trend towards increase for GluN2B levels. Consequently, GluN2A/2B ratio was markedly reduced in synaptic membranes of stressed rats.

Altogether, these data suggest that, after chronic stress exposure, in the face of a general reduction of NMDA receptors cellular levels, as indirectly indicated by the downregulation of the constitutively expressed GluN1 subunit, NMDA receptors with decreased GluN2A/2B ratio are enriched at synaptic membranes. This is suggestive of possible defects of synaptic activity and plasticity in stressed animals, which are not dampened in resilient rats or in by ketamine treated vulnerable rats.

In line with the hypothesis of altered synaptic function induced by chronic stress, previous studies consistently reported decreased LongTerm Potentiation (LTP) and Excitatory Post-Synaptic Currents (EPSCs) in the HPC of chronically stressed animals (Joels et al., 2012; Marsden, 2013).

Changes in AMPA and NMDA receptor subunits after chronic stress exposure were already evaluated in previous studies, although conflicting results were obtained depending on the stress protocol, the species, the strain, and/or the brain area considered. First, one study reported that chronic unpredictable stress induced a selective downregulation of AMPA receptors (and not NMDA receptors) in the HPC, while a loss of surface AMPA and NMDA receptor subunits was found in the prefrontal cortex (Kallarackal et al., 2013). Second, another study found that the expression of the obligatory GluN1, as well as of the accessory GluN2A and GluN2B subunits, increased in the ventral HPC of adult rats after CMS exposure for six weeks, at both mRNA and protein levels (Calabrese et al., 2012). Third, a recent study did not reveal any modification of GluN1 in the HPC, but increased expression in the prefrontal cortex from rats subjected to CMS for seven weeks (Pochwat et al., 2014).

\section{3. mGlu2 receptors}

mGlu2 is a presynaptic metabotropic glutamate receptor, whose activation negatively modulates glutamate release (Chaki et al., 2013); recent evidence has associated changes in mGlu2 levels with stress vulnerability (Nasca et al., 2015; Highland et al., 2019).

We observed that, both in HPC total extract and synaptic membranes, CMS selectively induced a decrease of mGlu2 in vulnerable rats, with no alterations in resilient animals. The present findings are in line with a previous study reporting that mice exposed to chronic stress showed decreased expression of mGlu2 in HPC and prefrontal cortex; however, while in the prefrontal cortex the reduction was significant in all stressed animals, in the HPC the reduction of mGlu2 was selectively found in vulnerable mice (Nasca et al., 2015).

The receptor has also gained attention as putative target for the development of novel antidepressants, with both agonists and antagonists under study (Chaki et al., 2013; Bruno et al., 2017; Lundstrom et al., 2017; O'Brien et al., 2018).

In the present work, we found for the first time that acute antidepressant treatment with ketamine was able to completely rescue the reduction of mGlu2 levels induced in the HPC of vulnerable animals by chronic stress. Although the functional outcomes of these changes on glutamate neurotransmission remain elusive, our results further support the involvement of mGlu2 in stress susceptibility and antidepressant response. In line with this hypothesis, a recent paper demonstrated that acute treatment with the mGlu2 positive allosteric modulator LY487379 rescued the depressive-like phenotype, as well as electrophysiological alterations, induced in the HPC of mice subjected to chronic restraint stress (Mango et al., 2019).

\subsection{Limitation of the study}

First, only male rats were included in the experimental protocol, despite the markedly higher prevalence of major depression among women compared to men (Kuehner, 2017). A large number of clinical and preclinical evidence documented sex differences in brain anatomy, chemistry, and function, as well as in stress and drug responses (Bangasser and Valentino, 2014; Labonté et al., 2017; Sarkar and Kabbaj, 2016; Herzog et al., 2020). Previous studies showed both behavioral and neurobiological sex differences in the CMS model of depression (reviewed in Franceschelli et al., 2014), as well as in ketamine response (Strong and Kabbaj, 2018; Ardalan et al., 2020). In the present explorative study it was chosen to use male rats only. Further work is warranted to analyse sex differences in the CMS model.

Second, we analyzed the whole hippocampus without differentiating between dorsal and ventral sub-regions. It is believed that the dorsal hippocampus, interfacing with cortical regions involved in information processing, performs primarily cognitive functions, while the ventral hippocampus, projecting to other structures of the limbic system (i.e. amygdala, nucleus accumbens and hypothalamus), is involved primarily in emotional behavior and motivation (Fanselow and Dong, 2010; Lee et al., 2017).

In the present explorative study, we decided to use the whole hippocampus, without dividing in dorsal and ventral, to find general modifications in glutamate receptors expression and regulation in the area.

Finally, we decided to treat with ketamine only animals vulnerable to CMS and not naïve and resilient ones. Indeed, it is important to notice that previous work reported that subanesthetic ketamine has no 
effect on sucrose intake in naïve animals (Autry et al., 2011). Moreover, in a separate set of animals, we found no effect of ketamine in the sucrose preference test in CMS-R rats (Tornese et al., 2019). Taken together, these results show that ketamine affects hedonic behavior only in animals subjected to chronic stress.

\section{Conclusion}

In the present study, we found that CMS induces in HPC alterations of ionotropic glutamate receptors expression, phosphorylation and localization at synaptic membranes, which are generally independent on stress vulnerability/resilience and not affected by antidepressant ketamine treatment. Interestingly, main alterations were found at synaptic level, where an enrichment of GluA2-containing AMPA receptors and NR2B-containing NMDA receptors was measured in stressed animals. These results are in line with a hypofunction of activity-dependent glutamatergic synaptic transmission induced by chronic stress exposure, as previously reported by other authors in several animal models of depression (as a recent review, see (Duman et al., 2019).

On the other hand, a completely different role in the response to stress and ketamine treatment seems to be played by metabotropic glutamate receptors, especially the mGlu2 subunit. Indeed, mGlu2 undergoes a selective downregulation in vulnerable animals, which is completely restored by acute ketamine treatment. This suggests a possible functional role of mGlu2 in regulating stress vulnerability and fast antidepressant response, as previously hypothesized (Nasca et al., 2015; Nasca et al., 2017), but never shown before for acute ketamine treatment.

\section{Funding}

This work was supported by research grants from the Italian Ministry of University (PRIN project n. 2015HRE757) and from Cariplo Foundation (grant: 2017-0620).

\section{Ethical statement}

Experiments were performed in accordance with the European Community Council Directive 2010/63/UE and approved by the Italian legislation on animal experimentation (Decreto Legislativo 26/2014, authorization N 308/2015-PR).

\section{Author statement}

$\mathrm{AB}, \mathrm{LM}$ and MP conceive the study and designed the experimental workflow. ME, GC, JM, PT, NS performed the experiments. FB, CF, LLV collaborated in the discussion of the data and in the critical revision of the manuscript. $\mathrm{AB}$ and $\mathrm{LM}$ wrote the manuscript. $\mathrm{AB}$ and MP got funds for this study. All co-authors read and approved the final version of the manuscript.

\section{Declaration of Competing Interest}

None.

\section{References}

Anggono, V., Huganir, R.L., 2012. Regulation of AMPA receptor trafficking and synaptic plasticity. Curr. Opin. Neurobiol. 22, 461-469.

Ardalan, M., Elfving, B., Rafati, A.H., Mansouri, M., Zarate Jr., C.A., Mathe, A.A., Wegener, G., 2020. Rapid effects of S-ketamine on the morphology of hippocampal astrocytes and BDNF serum levels in a sex-dependent manner. Eur. Neuropsychopharmacol. 32, 94-103.

Autry, A.E., Adachi, M., Nosyreva, E., Na, E.S., Los, M.F., Cheng, P.F., Kavalali, E.T. Monteggia, L.M., 2011. NMDA receptor blockade at rest triggers rapid behavioural antidepressant responses. Nature. 475, 91-95.

Bangasser, D.A., Valentino, R.J., 2014. Sex differences in stress-related psychiatric disorders: neurobiological perspectives. Front. Neuroendocrinol. 35, 303-319.
Barbon, A., Fumagalli, F., Caracciolo, L., Madaschi, L., Lesma, E., Mora, C., Carelli, S., Slotkin, T.A., Racagni, G., Di Giulio, A.M., Gorio, A., Barlati, S., 2010. Acute spinal cord injury persistently reduces R/G RNA editing of AMPA receptors. J. Neurochem. 114, 397-407.

Bellone, C., Nicoll, R.A., 2007. Rapid bidirectional switching of synaptic NMDA receptors. Neuron 55, 779-785.

Bigio, B., Mathe, A.A., Sousa, V.C., Zelli, D., Svenningsson, P., McEwen, B.S., Nasca, C., 2016. Epigenetics and energetics in ventral hippocampus mediate rapid antidepressant action: implications for treatment resistance. Proc. Natl. Acad. Sci. U. S. A. 113, 7906-7911.

Bonini, D., Filippini, A., La Via, L., Fiorentini, C., Fumagalli, F., Colombi, M., Barbon, A., 2015. Chronic glutamate treatment selectively modulates AMPA RNA editing and ADAR expression and activity in primary cortical neurons. RNA Biol. 12, 43-53.

Bonini, D., Mora, C., Tornese, P., Sala, N., Filippini, A., La Via, L., Milanese, M., Calza, S., Bonanno, G., Racagni, G., Gennarelli, M., Popoli, M., Musazzi, L., Barbon, A., 2016. Acute Footshock stress induces time-dependent modifications of AMPA/NMDA protein expression and AMPA phosphorylation. Neural plasticity 2016, 7267865.

Bruno, V., Caraci, F., Copani, A., Matrisciano, F., Nicoletti, F., Battaglia, G., 2017. The impact of metabotropic glutamate receptors into active neurodegenerative processes: a "dark side" in the development of new symptomatic treatments for neurologic and psychiatric disorders. Neuropharmacology 115, 180-192.

Calabrese, F., Guidotti, G., Molteni, R., Racagni, G., Mancini, M., Riva, M.A., 2012. Stressinduced changes of hippocampal NMDA receptors: modulation by duloxetine treatment. PLoS One 7, e37916.

Chaki, S., Ago, Y., Palucha-Paniewiera, A., Matrisciano, F., Pilc, A., 2013. mGlu2/3 and mGlu5 receptors: potential targets for novel antidepressants. Neuropharmacology 66, 40-52.

Del Giudice, M., Ellis, B.J., Shirtcliff, E.A., 2011. The adaptive calibration model of stress responsivity. Neurosci. Biobehav. Rev. 35, 1562-1592.

Duman, R.S., Sanacora, G., Krystal, J.H., 2019. Altered connectivity in depression: GABA and glutamate neurotransmitter deficits and reversal by novel treatments. Neuron 102, 75-90.

Fanselow, M.S., Dong, H.W., 2010. Are the dorsal and ventral hippocampus functionally distinct structures? Neuron. 65, 7-19.

Ferraguti, F., Shigemoto, R., 2006. Metabotropic glutamate receptors. Cell Tissue Res. 326, 483-504.

Filippini, A., Bonini, D., La Via, L., Barbon, A., 2017. The good and the bad of glutamate receptor RNA editing. Mol. Neurobiol. 54, 6795-6805.

Franceschelli, A., Herchick, S., Thelen, C., Papadopoulou-Daifoti, Z., Pitychoutis, P.M., 2014. Sex differences in the chronic mild stress model of depression. Behav. Pharmacol. 25, 372-383.

Han, M.H., Nestler, E.J., 2017. Neural substrates of depression and resilience. Neurotherapeutics 14, 677-686.

Herzog, D.P., Mellema, R.M., Remmers, F., Lutz, B., Müller, M.B., Treccani, G., 2020. Sexually dimorphic Behavioral profile in a transgenic model enabling targeted recombination in active neurons in response to ketamine and $(2 R, 6 R)$ Hydroxynorketamine administration. Int. J. Mol. Sci 21 pii E2142.

Highland, J.N., Zanos, P., Georgiou, P., Gould, T.D., 2019. Group II metabotropic glutamate receptor blockade promotes stress resilience in mice. Neuropsychopharmacology 44, 1788-1796.

Ieraci, A., Mallei, A., Popoli, M., 2016. Social isolation stress induces anxious-depressivelike behavior and alterations of neuroplasticity-related genes in adult male mice. Neural plasticity 2016, 6212983.

Izzi, C., Barbon, A., Kretz, R., Sander, T., Barlati, S., 2002. Sequencing of the GRIK1 gene in patients with juvenile absence epilepsy does not reveal mutations affecting receptor structure. Am. J. Med. Genet. 114, 354-359.

Joels, M., Baram, T.Z., 2009. The neuro-symphony of stress. Nat. Rev. Neurosci. 10, 459-466.

Joels, M., Sarabdjitsingh, R.A., Karst, H., 2012. Unraveling the time domains of corticosteroid hormone influences on brain activity: rapid, slow, and chronic modes. Pharmacol. Rev. 64, 901-938.

Kadriu, B., Musazzi, L., Henter, I.D., Graves, M., Popoli, M., Zarate Jr., C.A., 2019. Glutamatergic neurotransmission: pathway to developing novel rapid-acting antidepressant treatments. Int. J. Neuropsychopharmacol. 22, 119-135.

Kallarackal, A.J., Kvarta, M.D., Cammarata, E., Jaberi, L., Cai, X., Bailey, A.M., Thompson, S.M., 2013. Chronic stress induces a selective decrease in AMPA receptormediated synaptic excitation at hippocampal temporoammonic-CA1 synapses. J. Neurosci. 33, 15669-15674.

Kraus, C., Lanzenberger, R., Kasper, S., 2017. Ketamine for the treatment of depression. JAMA psychiatry 74, 970.

Kraus, C., Wasserman, D., Henter, I.D., Acevedo-Diaz, E., Kadriu, B., Zarate Jr., C.A., 2019. The influence of ketamine on drug discovery in depression. Drug Discov. Today 24, 2033-2043.

Kuehner, C., 2017. Why is depression more common among women than among men? Lancet Psychiatry 4, 146-158.

La Via, L., Bonini, D., Russo, I., Orlandi, C., Barlati, S., Barbon, A., 2013. Modulation of dendritic AMPA receptor mRNA trafficking by RNA splicing and editing. Nucleic Acids Res. 41, 617-631.

Labonté, B., Engmann, O., Purushothaman, I., Menard, C., Wang, J., Tan, C., Scarpa, J.R., Moy, G., Loh, Y.E., Cahill, M., Lorsch, Z.S., Hamilton, P.J., Calipari, E.S., Hodes, G.E., Issler, O., Kronman, H., Pfau, M., Obradovic, A.L.J., Dong, Y., Neve, R.L., Russo, S., Kazarskis, A., Tamminga, C., Mechawar, N., Turecki, G., Zhang, B., Shen, L., Nestler, E.J., 2017. Sex-specific transcriptional signatures in human depression. Nat. Med. 23, 1102-1111.

Lee, A.R., Kim, J.H., Cho, E., Kim, M., Park, M., 2017. Dorsal and ventral Hippocampus differentiate in functional pathways and differentially associate with neurological 
disease-related genes during postnatal development. Front. Mol. Neurosci. 10, 331

Lener, M.S., Niciu, M.J., Ballard, E.D., Park, M., Park, L.T., Nugent, A.C., Zarate Jr., C.A., 2017. Glutamate and gamma-Aminobutyric acid Systems in the Pathophysiology of major depression and antidepressant response to ketamine. Biol. Psychiatry 81, 886-897.

Li, N., Liu, R.J., Dwyer, J.M., Banasr, M., Lee, B., Son, H., Li, X.Y., Aghajanian, G., Duman, R.S., 2011. Glutamate N-methyl-D-aspartate receptor antagonists rapidly reverse behavioral and synaptic deficits caused by chronic stress exposure. Biol. Psychiatry 69, 754-761.

Liu, R.J., Aghajanian, G.K., 2008. Stress blunts serotonin- and hypocretin-evoked EPSCs in prefrontal cortex: role of corticosterone-mediated apical dendritic atrophy. Proc. Natl. Acad. Sci. U. S. A. 105, 359-364.

Lohmann, C., Kessels, H.W., 2014. The developmental stages of synaptic plasticity. J. Physiol. 592, 13-31.

Lu, W., Roche, K.W., 2012. Posttranslational regulation of AMPA receptor trafficking and function. Curr. Opin. Neurobiol. 22, 470-479.

Lundstrom, L., Bissantz, C., Beck, J., Dellenbach, M., Woltering, T.J., Wichmann, J., Gatti, S., 2017. Reprint of pharmacological and molecular characterization of the positive allosteric modulators of metabotropic glutamate receptor 2. Neuropharmacology $115,115-127$.

Malenka, R.C., Bear, M.F., 2004. LTP and LTD: an embarrassment of riches. Neuron 44, $5-21$.

Mango, D., Caruso, A., Saidi, A., Nistico, R., Scaccianoce, S., 2019. The positive allosteric modulator at mGlu2 receptors, LY487379, reverses the effects of chronic stress-induced behavioral maladaptation and synaptic dysfunction in the adulthood. Synapse 73, e22101.

Marsden, W.N., 2013. Synaptic plasticity in depression: molecular, cellular and functional correlates. Prog. Neuro-Psychopharmacol. Biol. Psychiatry 43, 168-184.

McEwen, B.S., 2013. The brain on stress: toward an integrative approach to brain, body, and behavior. Perspect. Psychol. Sci. 8, 673-675.

McEwen, B.S., 2017. Allostasis and the epigenetics of brain and body health over the life course: the brain on stress. JAMA psychiatry 74, 551-552.

McEwen, B.S., Bowles, N.P., Gray, J.D., Hill, M.N., Hunter, R.G., Karatsoreos, I.N., Nasca, C. 2015. Mechanisms of stress in the brain. Nat. Neurosci. 18, 1353-1363.

McEwen, B.S., Nasca, C., Gray, J.D., 2016. Stress effects on neuronal structure: Hippocampus, amygdala, and prefrontal cortex. Neuropsychopharmacology 41, 3-23.

Moda-Sava, R.N., Murdock, M.H., Parekh, P.K., Fetcho, R.N., Huang, B.S., Huynh, T.N., Witztum, J., Shaver, D.C., Rosenthal, D.L., Alway, E.J., et al., 2019. Sustained rescue of prefrontal circuit dysfunction by antidepressant-induced spine formation. Science 364.

Morley-Fletcher, S., Mairesse, J., Soumier, A., Banasr, M., Fagioli, F., Gabriel, C., Mocaer, E., Daszuta, A., McEwen, B., Nicoletti, F., et al., 2011. Chronic agomelatine treatment corrects behavioral, cellular, and biochemical abnormalities induced by prenatal stress in rats. Psychopharmacology 217, 301-313.

Musazzi, L., Milanese, M., Farisello, P., Zappettini, S., Tardito, D., Barbiero, V.S., Bonifacino, T., Mallei, A., Baldelli, P., Racagni, G., et al., 2010. Acute stress increases depolarization-evoked glutamate release in the rat prefrontal/frontal cortex: the dampening action of antidepressants. PLoS One 5, e8566.

Musazzi, L., Tornese, P., Sala, N., Popoli, M., 2017a. Acute or chronic? A stressful question. Trends Neurosci. 40, 525-535.

Musazzi, L., Tornese, P., Sala, N., Popoli, M., 2017b. Acute stress is not acute: sustained enhancement of glutamate release after acute stress involves readily releasable pool size and synapsin I activation. Mol. Psychiatry 22, 1226-1227.

Nasca, C., Zelli, D., Bigio, B., Piccinin, S., Scaccianoce, S., Nistico, R., McEwen, B.S., 2015. Stress dynamically regulates behavior and glutamatergic gene expression in hippocampus by opening a window of epigenetic plasticity. Proc. Natl. Acad. Sci. U. S. A. $112,14960-14965$.

Nasca, C., Bigio, B., Zelli, D., de Angelis, P., Lau, T., Okamoto, M., Soya, H., Ni, J., Brichta, L., Greengard, P., et al., 2017. Role of the Astroglial glutamate exchanger xCT in ventral Hippocampus in resilience to stress. Neuron 96, 402-413 e405.

O'Brien, D.E., Shaw, D.M., Cho, H.P., Cross, A.J., Wesolowski, S.S., Felts, A.S., Bergare, J., Elmore, C.S., Lindsley, C.W., Niswender, C.M., et al., 2018. Differential pharmacology and binding of mGlu2 receptor allosteric modulators. Mol. Pharmacol. 93, 526-540.

Orlandi, C., La Via, L., Bonini, D., Mora, C., Russo, I., Barbon, A., Barlati, S., 2011. AMPA receptor regulation at the mRNA and protein level in rat primary cortical cultures. PLoS One 6, e25350.

Ozbay, F., Fitterling, H., Charney, D., Southwick, S., 2008. Social support and resilience to stress across the life span: a neurobiologic framework. Curr. Psychiatry Rep. 10, 304-310.

Peterlik, D., Flor, P.J., Uschold-Schmidt, N., 2016. The emerging role of metabotropic glutamate receptors in the pathophysiology of chronic stress-related disorders. Curr. Neuropharmacol. 14, 514-539.

Pochwat, B., Szewczyk, B., Sowa-Kucma, M., Siwek, A., Doboszewska, U., Piekoszewski, W., Gruca, P., Papp, M., Nowak, G., 2014. Antidepressant-like activity of magnesium in the chronic mild stress model in rats: alterations in the NMDA receptor subunits. Int. J. Neuropsychopharmacol. 17, 393-405.

Popoli, M., Yan, Z., McEwen, B.S., Sanacora, G., 2011. The stressed synapse: the impact of stress and glucocorticoids on glutamate transmission. Nat. Rev. Neurosci. 13, 22-37.

Russo, I., Bonini, D., Via, L.L., Barlati, S., Barbon, A., 2013. AMPA receptor properties are modulated in the early stages following pilocarpine-induced status epilepticus. NeuroMolecular Med. 15, 324-338.

Sanacora, G., Treccani, G., Popoli, M., 2012. Towards a glutamate hypothesis of depression: an emerging frontier of neuropsychopharmacology for mood disorders. Neuropharmacology 62, 63-77.

Sanz-Clemente, A., Nicoll, R.A., Roche, K.W., 2013. Diversity in NMDA receptor composition: many regulators, many consequences. The Neuroscientist 19, 62-75.

Sarkar, A., Kabbaj, M., 2016. Sex differences in effects of ketamine on behavior, spine density, and synaptic proteins in socially isolated rats. Biol. Psychiatry 80, 448-456.

Strekalova, T., Couch, Y., Kholod, N., Boyks, M., Malin, D., Leprince, P., Steinbusch, H.M., 2011. Update in the methodology of the chronic stress paradigm: internal control matters. Behav. Brain functions 7, 9.

Strong, C.E., Kabbaj, M., 2018. On the safety of repeated ketamine infusions for the treatment of depression: effects of sex and developmental periods. Neurobiol. Stress. 9, 166-175.

Tornese, P., Sala, N., Bonini, D., Bonifacino, T., La Via, L., Milanese, M., Treccani, G. Seguini, M., Ieraci, A., Mingardi, J., et al., 2019. Chronic mild stress induces anhedonic behavior and changes in glutamate release, BDNF trafficking and dendrite morphology only in stress vulnerable rats. The rapid restorative action of ketamine. Neurobiol. Stress 10, 100160

Treccani, G., Musazzi, L., Perego, C., Milanese, M., Nava, N., Bonifacino, T., Lamanna, J., Malgaroli, A., Drago, F., Racagni, G., et al., 2014. Stress and corticosterone increase the readily releasable pool of glutamate vesicles in synaptic terminals of prefrontal and frontal cortex. Mol. Psychiatry 19, 433-443.

Wang, J.Q., Guo, M.L., Jin, D.Z., Xue, B., Fibuch, E.E., Mao, L.M., 2014. Roles of subunit phosphorylation in regulating glutamate receptor function. Eur. J. Pharmacol. 728, 183-187.

Willner, P., 2017. Reliability of the chronic mild stress model of depression: a user survey. Neurobiol. Stress 6, 68-77.

Yashiro, K., Philpot, B.D., 2008. Regulation of NMDA receptor subunit expression and its implications for LTD, LTP, and metaplasticity. Neuropharmacology 55, 1081-1094.

Yuen, E.Y., Liu, W., Karatsoreos, I.N., Feng, J., McEwen, B.S., Yan, Z., 2009. Acute stress enhances glutamatergic transmission in prefrontal cortex and facilitates working memory. Proc. Natl. Acad. Sci. U. S. A. 106, 14075-14079.

Yuen, E.Y., Wei, J., Liu, W., Zhong, P., Li, X., Yan, Z., 2012. Repeated stress causes cognitive impairment by suppressing glutamate receptor expression and function in prefrontal cortex. Neuron 73, 962-977.

Zanos, P., Moaddel, R., Morris, P.J., Georgiou, P., Fischell, J., Elmer, G.I., Alkondon, M., Yuan, P., Pribut, H.J., Singh, N.S., et al., 2016. NMDAR inhibition-independent antidepressant actions of ketamine metabolites. Nature 533, 481-486.

Zanos, P., Highland, J.N., Stewart, B.W., Georgiou, P., Jenne, C.E., Lovett, J., Morris, P.J., Thomas, C.J., Moaddel, R., Zarate Jr., C.A., et al., 2019. (2R,6R)-hydroxynorketamine exerts mGlu2 receptor-dependent antidepressant actions. Proc. Natl. Acad. Sci. U. S. A. $116,6441-6450$. 